\title{
Changes in Sustained Treatment Response in Relapsed Chronic Hepatitis C Egyptian Patients on Directly Acting Antiviral Agents with Increased Insulin Resistance
}

\author{
Inas Elkhedr Mohamed ${ }^{* 1}$, Yasser Omar Abdel Rahman ${ }^{1}$, Ramy Samir Ghait ${ }^{1}$, Alaa Lotfy ElSayed ${ }^{2}$ \\ ${ }^{1}$ Department of Internal Medicine, Faculty of Medicine, Ain Shams University, Egypt. \\ ${ }^{2}$ Kobri Alqoba Military Hospital, Egypt \\ *Corresponding author: Inas Elkhedr Mohamed, Mobile: (+20) 01093351447, E-Mail: inas_elkhedr@yahoo.com
}

\begin{abstract}
Background: It is known that patients with high insulin resistance (IR) have a slower rate of decline in the viral load of HCV RNA compared to patients with low IR.

Objective: to evaluate relation between insulin resistance on sustained treatment response with direct oral antiviral drugs on relapsed Egyptian chronic HCV patients.

Patients and Methods: 50 patients with chronic hepatitis $\mathrm{C}$ met inclusion criteria divided into Group I were non responders to treatment and achieved sustained virological response (SVR) at week 12 on retreatment and Group II were non responders to treatment and failed to attain SVR after 12 weeks of retreatment. All participants received the direct antiviral therapy (DAA) sofosbuvir and daclatasvir for 12 weeks. HOMA-IR was calculated and PCR was done before treatment, at end of treatment, 12 weeks and 3 months after end of treatment.

Results: there was a highly significant correlation between HOMA-IR and liver enzymes, lipid $(\mathrm{P}<0.01)$ and significant relation between HOMA-IR and BMI and waist circumference. After 6 months of treatment there was highly significant increase in insulin sensitivity and decrease in insulin resistance in patients after eradication of HCV $(\mathrm{P}<0.01) .12$ cases of insulin resistance pretreatment and after 6 months: 3 cases HCV -ve became noninsulin resistant, 2 cases HCV -ve became insulin resistant, 2 cases of HCV -ve developed DM and 5 cases had no changes (still insulin resistant).
\end{abstract}

Conclusion: prevalence of insulin resistance and diabetes mellitus in patients with chronic hepatitis $\mathrm{C}$ was due to multiple causes and clearance of HCV infection improves insulin resistance; not directly related to DAA.

Keywords: Chronic hepatitis C, Directly acting antiviral agents, Insulin resistance, SVR.

\section{INTRODUCTION}

Insulin resistance (IR) development known to be associated with chronic hepatitis $\mathrm{C}$ and predispose to type- 2 diabetes, this is not related to type or severity of liver disease, but through interactions with different components of the insulin signaling pathway and its regulation ${ }^{(1)}$. In addition, patients with high IR have a slower rate of decline in the viral load of HCV RNA compared to patients with low IR, even in the first $24 \mathrm{~h}$ of treatment. Moreover, a higher degree of IR and a lower rate of rapid viral response in genotypes 1, 3 and 4; and most likely not achieving sustained virological response (SVR) ${ }^{(2)}$.

The direct-acting anti-viral treatments (DAA) achieve SVRs of more than $90 \%$ for most treatment groups. A former study suggested that metabolic factors such as diabetes and hyperlipidemia compromise the effect of DAA treatment ${ }^{(3)}$. Furthermore, study of host-related factors have been revealed interference with $\mathrm{HCV}$ treatment response, including: old age, male gender, ethnicity, obesity, advanced liver fibrosis or cirrhosis, high transaminase levels, set up a state of diabetes, HLA class, and host genetic polymorphisms ${ }^{(4)}$.
Aim of the work was to evaluation of relation between insulin resistance on sustained treatment response with direct oral antiviral drugs (DAA) on relapsed Egyptian chronic HCV patients.

\section{Patients and methods:}

The study included 50 patients with chronic hepatitis $\mathrm{C}$ who relapsed after DAA treatment. Patients were recruited over a period of six months (October 2017 to March 2018) from Ain Shams University Hospital and Kobri El Kobba Military Hospital who were attending outpatient clinic.

Ethical approval:

The study was performed according to the ethical standards. Faculty of Medicine, Ain Shams University Ethical Committee approval was taken before starting the study. Written informed consent was obtained from all participants before enrolment in the study.

The patients were divided into two groups: Group I (included 25 patients who were non responders to treatment and achieved sustained virological response (SVR) at week 12 on retreatment) and Group II (included 25 patients who were non responders to treatment and also failed to attain (SVR) after 12 weeks of retreatment.

This article is an open access article distributed under the terms and conditions of the Creative Commons Attribution (CC BY-SA) license (http://creativecommons.org/licenses/by/4.0/) 
All the following were excluded from the study: HBV and HIV infection, patients with cirrhotic liver (excluded by Fibroscan), chronic renal diseases, diabetes mellitus, hepatocellular carcinoma (HCC), over weight (BMI >30), age less than 18 years.

All participants received the direct antiviral therapy (DAA) sofosbuvir and daclatasvir for 12 weeks according to the protocol of the National Committee for the control of Viral Hepatitis (NCCVH) and were evaluated by the sustained virological response which is negative PCR at 12 weeks.

All participants underwent: full history taking, full clinical examination, laboratory tests (Fasting and postprandial blood sugar, HbA1C, CBC, Serum bilirubin, ALT, AST, PT, Alfa Fetoprotein, Serum Albumin, HBs Ag, HCV Ab, Serum creatinine, Na, $\mathrm{K}$, Complete lipid profile).

- Imaging techniques: Abdominal Ultrasound, triphasic $\mathrm{CT}$ abdomen if needed.

- Hepatitis C virus (RNA) PCR for all patients with chronic hepatitis $\mathrm{C}$ (before treatment, at end of treatment 12 weeks and 3 months after end of treatment).

- Calculation of BMI: Weight in $\mathrm{Kg} /$ Height in meters $^{2}$. Waist circumference was measured with a non-elastic measuring tape, in centimeters. Other physical examinations were performed 6 months after therapy.

-Calculation of insulin resistance (IR): Insulin resistance was calculated through the HOMA method as follows: HOMA = fasting serum insulin $(\mu \mathrm{u} / \mathrm{ml}) X$ serum glucose $(\mathrm{mmol} / \mathrm{dL}) / 22.5$.

Patients were fasting for 12 hours before a blood sample was taken for the fasting insulin and serum glucose. Fasting insulin was measured in blood using
(ELISA) kit (Ultrasensitive Rat Insulin ELISA). Fasting Insulin: 2.6-25.6 $\mu \mathrm{IU} / \mathrm{mL}$. Patients were categorized as insulin resistant if HOMA was greater than 2 and diabetics if greater than $4^{(5)}$.

\section{Statistical analysis}

Data were analyzed using Statistical Package for the Social Science (SPSS) version 17.0. Quantitative data were expressed as mean \pm standard deviation (SD). Qualitative data were expressed as frequency and percentage. The following tests were done: Independent-samples T test, Mann-Whitney U test, Chi-square $\left(\mathrm{X}^{2}\right)$ test of significance, Pearson's correlation coefficient (r) test was used for correlating data. Probability (P-value) less than 0.05 was considered significant and less than 0.01 was considered as highly significant.

\section{RESULTS}

50 patients with chronic hepatitis $\mathrm{C}$ met inclusion criteria divided into Group I were non responders to treatment and achieved sustained virological response (SVR) at week 12 on retreatment and Group II were non responders to treatment and failed to attain SVR after 12 weeks of retreatment.

The study included 50 chronic HCV patients who were non-responder to DAA. Group I: achieved SVR after retreatment at 12 weeks were all males, average age between (38-55) years. Group II: failed to attain SVR after 12 weeks of retreatment were 25 males, average age between (39-56) years.

A high significant decrease had occurred in liver enzymes (Table 1).

Table (1): Comparison between group I before and after treatment as regard their demographic and laboratory data

\begin{tabular}{|c|c|c|c|c|c|}
\hline & \multicolumn{2}{|c|}{ Group I $(\mathrm{N}=25)$} & \multirow{2}{*}{$\begin{array}{c}\text { Mean } \\
\text { difference }\end{array}$} & \multirow{2}{*}{$\mathbf{P}$} & \multirow{2}{*}{ Sig } \\
\hline & Before $\mathrm{ttt}$ & After ttt & & & \\
\hline BMI $\left(\mathrm{Kg} / \mathrm{m}^{2}\right)$ & $25.69 \pm 1.42$ & $25.68 \pm 1.26$ & 0.010 & $>0.05$ & NS \\
\hline Waist Circum (cm) & $88.27 \pm 4.20$ & $87.67 \pm 2.88$ & 0.600 & $>0.05$ & NS \\
\hline $\operatorname{AST}(\mathbf{u} / \mathbf{l})$ & $65.40 \pm 15.88$ & $52.10 \pm 10.56$ & 13.300 & $<0.01$ & HS \\
\hline $\operatorname{ALT}(\mathbf{u} / \mathbf{l})$ & $70.80 \pm 9.19$ & $58.73 \pm 5.87$ & 12.067 & $<0.01$ & HS \\
\hline Albumin (g/dl) & $4.18 \pm 0.38$ & $4.19 \pm 0.32$ & -0.003 & $>0.05$ & NS \\
\hline PT (second) & $12.92 \pm 0.66$ & $12.81 \pm 0.51$ & 0.120 & $>0.05$ & NS \\
\hline Cholesterol (mg/dl) & $150.47 \pm 9.09$ & $155.77 \pm 4.82$ & -5.300 & $>0.05$ & NS \\
\hline TGs (mg/dl) & $138.40 \pm 4.88$ & $141.50 \pm 9.11$ & -3.100 & $>0.05$ & NS \\
\hline FBG (mg/dl) & $98.83 \pm 10.06$ & $102.40 \pm 16.76$ & -3.567 & $>0.05$ & NS \\
\hline PP (mg/dl) & $120.47 \pm 12.14$ & $124.23 \pm 22.05$ & -3.767 & $>0.05$ & NS \\
\hline $\mathrm{HbA}_{1 \mathrm{c}}(\%)$ & $5.61 \pm 0.61$ & $5.69 \pm 0.68$ & -0.080 & $>0.05$ & NS \\
\hline $\begin{array}{c}\text { Fasting Insulin } \\
(\mathrm{MU} / \mathrm{ml})\end{array}$ & $8.73 \pm 1.22$ & $8.92 \pm 1.91$ & -0.193 & $>0.05$ & NS \\
\hline HOMA-IR & $2.16 \pm 0.70$ & $2.31 \pm 0.83$ & -0.150 & $>0.05$ & NS \\
\hline
\end{tabular}

BMI: body mass index, TGs: triglyceride, FBG: fasting blood sugar, PP: post prandial blood sugar, HBA1c: glycosylated hemoglobin, HOMA-IR: Homeostatic Model Assessment of Insulin Resistance. 
A comparison of the group II at beginning of the study and after 6 months as regard their demographic and laboratory data showed that after 6 months there was highly significant increase in fasting insulin, PP glucose, HBA1C and HOMA-R (Table 2).

Table (2): Comparison between group GII at beginning of the study and after 6 months as regard their demographic and laboratory data

\begin{tabular}{|l|c|c|c|c|c|}
\hline \multirow{2}{*}{ BMI (Kg/m $)$} & \multicolumn{2}{|c|}{ Group G2 (N=25) } & \multirow{2}{*}{ Mean difference } & P & \multirow{2}{*}{ Sig } \\
\cline { 2 - 3 } & Basal & After 6 months & -0.0167 & $>0.05$ & NS \\
\hline Waist Circum (cm) & $88.77 \pm 1.42$ & $25.78 \pm 1.32$ & 0.433 & $>0.05$ & NS \\
\hline AST (u/l) & $62.43 \pm 8.95$ & $61.67 \pm 8.18$ & 0.767 & $>0.05$ & NS \\
\hline ALT (u/l) & $73.93 \pm 3.67$ & $72.87 \pm 2.71$ & 1.067 & $>0.05$ & NS \\
\hline Albumin (g/dl) & $4.38 \pm 0.50$ & $4.27 \pm 0.45$ & 0.107 & $>0.05$ & NS \\
\hline PT (second) & $12.79 \pm 0.60$ & $12.88 \pm 0.54$ & -0.090 & $>0.05$ & NS \\
\hline Cholesterol (mg/dl) & $162.73 \pm 36.53$ & $163.57 \pm 36.69$ & -0.833 & $>0.05$ & NS \\
\hline TGs (mg/dl) & $138.67 \pm 31.35$ & $142.97 \pm 31.82$ & -4.300 & $>0.05$ & NS \\
\hline FBG (mg/dl) & $95.27 \pm 10.66$ & $104.89 \pm 6.22$ & -9.627 & $>0.05$ & NS \\
\hline PP glucose (mg/dl) & $113.83 \pm 15.78$ & $134.13 \pm 30.71$ & -20.300 & $<0.01$ & HS \\
\hline HbA $(\%)$ & $5.49 \pm 0.62$ & $5.98 \pm 0.89$ & -0.490 & $<0.05$ & S \\
\hline $\begin{array}{l}\text { Fasting Insulin } \\
\text { (MU/ml) }\end{array}$ & $8.41 \pm 1.15$ & $10.21 \pm 2.53$ & -1.807 & $<0.01$ & HS \\
\hline HOMA-IR & $2.01 \pm 0.65$ & $2.82 \pm 0.07$ & -0.810 & $<0.01$ & HS \\
\hline
\end{tabular}

BMI: body mass index, TGs: triglyceride, FBG: fasting blood sugar, PP: post prandial blood sugar, HBA1c: glycosylated hemoglobin, HOMA-IR: Homeostatic Model Assessment of Insulin Resistance.

In group II there was a significant positive correlation between HOMA-IR and all of BMI, waist circumference, ALT, AST, cholesterol, TG, PP blood glucose and positive HCV infection and anegative correlation between HOMA-IR and serum albumin level (Table 3).

Table (3): Correlation between HOMA-IR and studied parameters in group II

\begin{tabular}{|l|c|c|c|}
\hline \multicolumn{3}{|c|}{ HOMA-IR } \\
\hline & Pearson correlation (r) & P & Sig. \\
\hline Age & 0.172 & $>0.05$ & NS \\
\hline BMI & 0.238 & $<0.05$ & S \\
\hline Waist circum. & 0.300 & $<0.05$ & S \\
\hline AST & 0.496 & $<0.01$ & HS \\
\hline ALT & 0.566 & $<0.01$ & HS \\
\hline Albumin & -0.178 & $>0.05$ & NS \\
\hline PT & 0.132 & $>0.05$ & NS \\
\hline Cholesterol & 0.541 & $<0.01$ & HS \\
\hline TGs. & 0.500 & $<0.01$ & HS \\
\hline PP glucose & 0.815 & $>0.01$ & HS \\
\hline HBA1c & 0.183 & $<0.01$ & NS \\
\hline HCV & 0.262 & HS \\
\hline
\end{tabular}


Table (4) showed that after 6 months of treatment there was highly significant increase in insulin sensitivity and decrease in insulin resistance in patients after eradication of HCV.

12 cases of insulin resistance pretreatment and after 6 months were as follows: 3 cases who became HCV -ve became non-insulin resistant. 2 cases who became HCV -ve became insulin resistant. 2 cases of HCV -ve developed DM and 5 cases had no changes (still insulin resistant). The other 13 cases that had no insulin resistance pretreatment and after 6 months had no changes after treatment.

Table (4): Comparison between group I at beginning of the study and after 6 months of treatment as regard HCV and HOMA-IR

\begin{tabular}{|c|c|c|c|c|}
\hline \multirow{2}{*}{ HOMA-IR } & Before ttt & After ttt & \multirow{2}{*}{ P } & \multirow{2}{*}{ Sig. } \\
\cline { 2 - 3 } & HCV +ve & HCV -ve & & \\
\multirow{2}{*}{ HOMA-IR } & 12 & 14 & \\
& $(48 \%)$ & $(56 \%)$ & \multirow{2}{*}{0.571} & NS \\
\hline \multirow{2}{*}{ Non IR } & 13 & 11 & \\
\hline Total & $(52 \%)$ & $(44 \%)$ & \\
\hline
\end{tabular}

The ROC Curve shows: Sensitivity of HOMA-IR was $100 \%$ while sensitivity of fasting insulin was $64 \%$. Specificity of HOMA-IR was only $44 \%$ while of fasting insulin was $68 \%$ (Table 5 and figure 1).

Table (5): Diagnostic tests of HOMA-IR and fasting insulin

\begin{tabular}{|l|c|c|c|c|c|c|}
\hline \multicolumn{1}{|c|}{ Variables } & Cut off point & AUC & Sensitivity & Specificity & +PV & -PV \\
\hline Fasting Insulin & $>9.9$ & 0.651 & 64.00 & 68.00 & 66.7 & 65.4 \\
\hline HOMA-IR & $>1.7$ & 0.638 & 100.00 & 44.00 & 64.1 & 100.0 \\
\hline
\end{tabular}

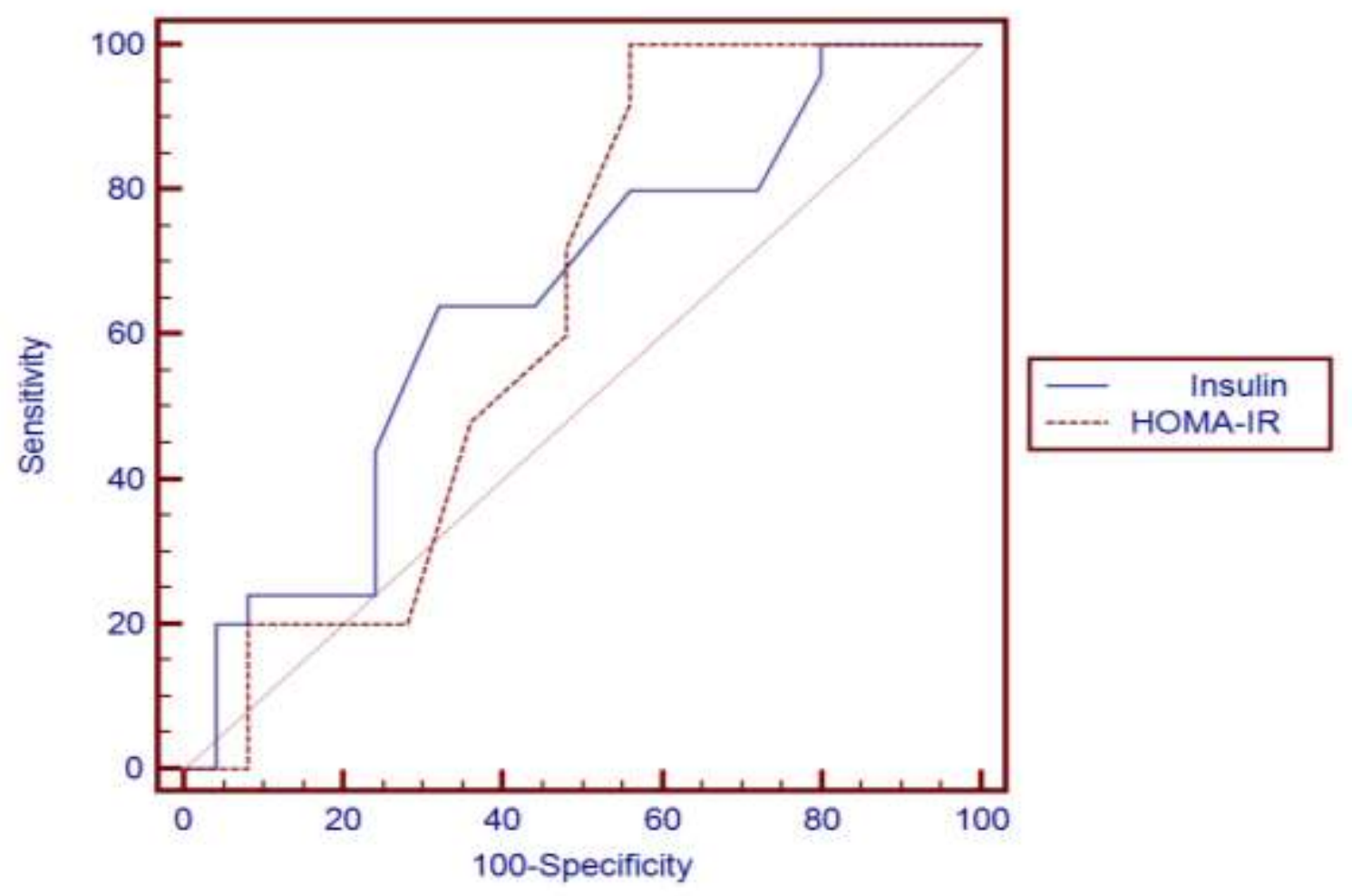

Figure (1) ROC curve for HOMA-IR and fasting insulin 


\section{DISCUSSION}

The evident role of IR in response failure to antiviral therapy among chronic HCV patients is supported by several studies ${ }^{(4)}$. In current study the prevalence of insulin resistance and DM in chronic hepatitis $\mathrm{C}$ patients, whether responder or nonresponder to treatment, was calculated and showed that the prevalence of insulin resistance is significantly higher in HCV patients who didn't respond to treatment and it is improved with successful antiviral therapy.

HCV patients' insulin resistance was correlated with BMI and waist circumference. In the present study there was a correlation between HOMA-IR and studied parameters in group II and highly significant relation between HOMA-IR and liver enzymes, lipid and significant relation between HOMA-IR and BMI and waist circumference. In contrast Yoneda et al. () ${ }^{(6)}$ found that HCV is directly associated with IR in a dose-dependent manner, independent of the visceral adipose tissue area.

The present study showed a high significant positive correlation between HCV and HOMA-IR, which was in agreement with all of the following study. Incidence of insulin resistance in chronic HCV infected patients was reported to be significantly higher than the general population ${ }^{(7)}$. Several prior studies also report IR, as measured by HOMA-IR, a predictor of lower sustained virologic response rate to anti-HCV therapy in naïve patients ${ }^{(8-10)}$.

Another observation in the present study that after 6 months, in group II of patients, there was highly significant increase in fasting insulin, PP glucose, HBA1C and HOMA-IR. In a retrospective cohort study of Stine $\boldsymbol{e t} \boldsymbol{a l} .{ }^{(11)}$ they demonstrated that $\mathrm{HbA1c}$ was unaffected by treatment of chronic HCV with DAA in patients with and without cirrhosis. However, this may in part be attributable to clinical management of diabetes and hyperglycemia with pharmacologic therapy rather than a primary process of viral clearance itself.

In group II there was a highly significant increase in HOMA-IR in HCV patients not responding to treatment after 6 months, but in group I in patients who achieved sustained virological response (SVR) at week 12 on retreatment, there was no significant changes. Because the number of patients developed insulin resistance in nonresponder was the same number of patients improved insulin resistance after eradication of $\mathrm{HCV}$, so the percentage of patients are almost nearly equal. These data denote that chronic hepatitis $\mathrm{C}$ (CHC) induces insulin resistance (IR) and subsequently diabetes.
12 cases of insulin resistance pretreatment and after 6 months: 3 cases HCV -ve became noninsulin resistant, 2 cases HCV -ve became insulin resistant, 2 cases of $\mathrm{HCV}$-ve developed DM and 5 cases had no changes (still insulin resistant).

The two patients who developed DM after 6 months of therapy had insulin resistant before treatment. So development of DM and increase of insulin resistance was significantly higher with failure to respond to treatment reflecting most probably direct effect of $\mathrm{HCV}$ and rather than the effect of therapy.

These results in agreement with many others. El Zayadi and Anis ${ }^{(12)}$ stated that HCV infection was an independent risk factor for the development of IR. Delgado-Borrego (13) stated that HCV suppression correlates with improvement in IR. These data provide further support for a role of $\mathrm{HCV}$ in the development of insulin resistance. Imazeki $\boldsymbol{e t}$ al. ${ }^{(14)}$ showed that HCV-infected patients showed a higher prevalence of DM and IR than those with HBV infection.

This indicates that there was a significant difference between the prevalence of insulin resistance and DM between chronic hepatitis $\mathrm{C}$ patients after successful eradication of hepatitis $\mathrm{C}$ infection improved insulin resistance but treatment with direct acting antiviral doesn't affect insulin resistance.

Yet, the previously assumed regimens of retreatment for relapsed patients with three months duration is only given to patients who received interferon and ribavirin, interferon and sofosbuvir and ribavirin, or sofosbuvir and ribavirin.

\section{CONCLUSION}

Prevalence of insulin resistance and diabetes mellitus in patients with chronic hepatitis $\mathrm{C}$ was due to multiple causes and clearance of $\mathrm{HCV}$ infection improves insulin resistance; not directly related to DAA. All patients presenting with chronic hepatitis $\mathrm{C}$ should be investigated for insulin resistance during or shortly after treatment.

Limitation of this study includes: the relatively small number of patients and a single regimen of DAA used.

Funding: This research did not receive any specific grant from funding agencies in the public, commercial, or not-for-profit sectors.

Conflict of interest: The authors declared that there was no conflict of interest. 


\section{REFERENCES}

1. Kralj D, Virović L, Stojsavljević S et al. (2016): Hepatitis C virus, insulin resistance, and steatosis. J Clin Transl Hepatol., 4(1): 66-75.

2. Knobler H, Malnick S (2016): Hepatitis $C$ and insulin action: An intimate relationship World $\mathrm{J}$ Hepatol., 8(2): 131-138.

3. Pawlotsky J, Chevaliez S, McHutchison J (2007): The hepatitis $\mathrm{C}$ virus life cycle as a target for new antiviral therapies. Gastroenterology, 132:19791998. 1

4. Abd El-Wahab E, Mikheal A, Sidkey F et al. (2015): Insulin resistance as a predictor of early virologic response to $\mathrm{HCV}$ therapy among chronic HCV Egyptian patients. Journal of Medical Virology, 87: 428-440

5. Maeno T, Okumura A, Ishikawa $T$ et al. (2003): Mechanisms of increased insulin resistance in noncirrhotic patients with chronic hepatitis $\mathrm{C}$ virus infection. J Gastroenterol Hepatol., 18:1358-63.

6. Yoneda M, Saito S, Ikeda T et al. (2007): Hepatitis $\mathrm{C}$ virus directly associates with insulin resistance independent of the visceral fat area in nonobese and nondiabetic patients. J Viral Hepat., 14: 600-7.

7. Miyajima M, Nakajima M, Motoi M et al. (2013): Leucine-rich $\alpha 2$-glycoprotein is a novel biomarker of neurodegenerative disease in human cerebrospinal fluid and causes neurodegeneration in mouse cerebral cortex. PLoS One, 8(9): 74453-8.
8. Romero-Gomez M, Del Mar Viloria M, Andrade $R$ et al. (2005): Insulin resistance impairs sustained response rate to peginterferon plus ribavirin in chronic hepatitis C patients. Gastroenterology, 128: 636-41.

9. Khattab M, Khader Y, Al-Khawaldeh A et al. (2010): Factors associated with poor glycemic control among patients with Type 2 diabetes. Journal of Diabetes and Its Complications, $24: 84-89$.

10. Eslam M, Lo'pez-Corte's L, Romero-Gomez M (2011): The role of insulin resistance in HIV/hepatitis C virus-coinfected patients. Current Opinion in HIV \& AIDS., 6(6): 553-558.

11. Stine G, Wynter J, Niccum B et al. (2017): Effect of treatment with direct acting antiviral on glycemic control in patients with diabetes mellitus and chronic hepatitis C. Ann Hepatol., 16 (2): 215-220.

12. El-Zayadi AR and Anis M (2012): Hepatitis C virus induced insulin resistance impairs response to anti viral therapy. World J Gastroenterol., 18(3): 212-224.

13. Delgado-Borrego A, Kamegaya $Y$, Jordan $S$ et al. (2011): HCV synergizes with body weight in the promotion of insulin resistance. J Viral Hepat., 18(2):135-41.

14. Imazeki F, Yokosuka O, Fukai K et al. (2008): Prevalence of diabetes mellitus and insulin resistance in patients with chronic hepatitis $\mathrm{C}$ : comparison with hepatitis B virus-infected and hepatitis C virus-cleared patients. Liver Int., 28(3): 355-62. 